\title{
Procesos de reestructuración urbana y niveles de vulnerabilidad a amenazas naturales en una ciudad de tamaño medio: La Serena, Chile (*)
}

\author{
Jorge Ortiz Véliz \\ jortiz@uchile.cl \\ Carmen Paz Castro Correa \\ cpcastro@uchile.cl \\ Departamento de Geografía Universidad de Chile \\ Av. Portugal 84, Santiago de Chile \\ Severino Escolano Utrilla \\ severino@unizar.es \\ Departamento de Geografía y Ordenación del Territorio \\ Universidad de Zaragoza
}

Recibido 20 de agosto 2003; versión corregida y aceptada, 30 julio 2004.

\section{RESUMEN}

En Latinoamérica, la investigación urbana ha estado centrada principalmente en las ciudades que ocupan la cúspide de los sistemas nacionales de asentamientos poblados. Se han estudiado, entre otros, sus efectos socioespaciales, funcionales y ambientales, en particular los referidos al crecimiento de las desigualdades, de la segregación y de las formas dispersas de la estructuración territorial. En la actualidad los procesos anteriormente aludidos comienzan a manifestarse también en el resto de las ciudades, en particular en las llamadas ciudades intermedias de los sistemas urbanos, las que constituyen una categoría de gran importancia en cuanto a su función articuladora del territorio a escala regional. En el presente trabajo el objetivo central es aportar conocimiento acerca de los procesos de cambio de las ciudades medias chilenas en el contexto de los procesos regionales antes nombrados. El área de estudio corresponde a la ciudad de La Serena, capital de la Región IV de Coquimbo, entidad emplazada en la región centro norte del país y que, de acuerdo con los resultados alcanzados, tiende a reproducir las estructuras, procesos espaciales y niveles de vulnerabilidad propias de las grandes ciudades. Los resultados muestran modificaciones en el modelo de distribución de las densidades de población, en la estructura de las centralidades, en los modos de expansión urbana y en el incremento de la segregación social.

Palabras clave: Dispersión urbana, segregación social, riesgos naturales, vulnerabilidad global.

\section{Processes of urban reorganization and natural hazard levels in a city of middle size: La Serena, Chile}

\begin{abstract}
The urban research in Latin America has been concentrated on the top cities of the national settlement system. Among the issues of research are the social spatial effects, environmental and functional effects and particularly those referred to unequal, segregated and sprawl urban growth. The former issues mentioned are thought to be present in other cities as well, particularly in middle size cities of the urban systems thus playing an important role on spatial structuring at regional scale. The present paper main contribution refers to increasing the knowledge of the changing processes of Chilean middle sizes cities at a regional scale context. The specific study area is the capital city of Coquimbo region named La Serena. It is located in the northern central part of Chile. Recent research results show that this city tends to reproduce largest cities structuring and spatial processes, as well as the modification of population distribution density model, centrality structures, urban sprawl growth and social segregation increasing.
\end{abstract}

Key words: Urban sprawl, social segregation, natural risk, global vulnerability.

(*) Proyecto FONDECYT N ${ }^{\circ} 1020107$

Proyecto FONDECYT N ${ }^{\circ} 7020107$ 


\section{INTRODUCCIÓN}

Las importantes transformaciones urbanas recientes asociadas a los cambios socioeconómicos y tecnológicos se han reflejado también en cambios significativos en el enfoque de los estudios sobre las ciudades y los sistemas urbanos (ZUMIN 1994). En efecto, la mundialización de la economía y determinadas peculiaridades del modelo postindustrial han reforzado la función de las ciudades como polos (económicos, culturales, ideológicos) del sistema mundial, al tiempo que la condición local se refuerza como lugares privilegiados de convivencia y relación. La dialéctica entre la escalas global-lo$\mathrm{cal}$, que en ocasiones se manifiesta de manera sutil, adquiere un renovado sentido al producirse en un nuevo contexto socioeconómico y tecnológico (THRIFT 1987; CAMAGNI 1991; CASTELLS 1995). En la región, la investigación urbana ha estado centrada principalmente en las grandes entidades, lo que ha permitido hablar de un tipo latinoamericano de ciudad. En efecto, los procesos de reestructuración y sus modalidades contradictorias de actuación han sido bastante estudiados para las ciudades que ocupan la cúspide de la jerarquía urbana mundial (CASTELLS et al. 1990; CASTELLS 1996). Es así como los modelos de la estructura funcional y socioespacial referenciados para las grandes ciudades muestran, entre otros aspectos, tendencias al cambio en la distribución de las densidades de población, en la estructura de las centralidades. en los modos de expansión urbana. Tambiên indican incremento de las migraciones internas, de las desigualdades y segregación social y consecuencias negativas para el ambiente.

En resumen, se camina hacia un modelo más frágil y posiblemente hacia una complejidad más ineficiente, ya que esta estructura se produce a costa del aumento del uso y consumo de recursos (suelo, agua, energía) generando un crecimiento no sustentable. En ocasiones, la población ocupa espacios expuestos a amenazas naturales, desarrollándose barrios al margen del funcionamiento de la ciudad.
CHARDON (2002) observa que esto ha provocado marginalización espacial caracterizada por una subintegración económica, que tiene asociada además una fuerte vulnerabilidad a la ocurrencia de desastres naturales.

En la actualidad los procesos anteriormente aludidos comienzan a ser patentes también en el resto de las ciudades, en particular en las llamadas "ciudades medias, intermedias o medianas" de los sistemas urbanos nacionales, asentamientos poblacionales que constituyen una categoría urbana de gran importancia en cuanto a su función articuladora del territorio a escala regional.

Sin embargo, salvo lo planteado por MERTINS (2000), no se ha llegado conformar un modelo, ni generalizaciones suficientes y útiles capaces de dar cuenta de las características propias de este grupo de ciudades. Ello por varias razones, entre otras la ambiguiedad implícita en su delimitación y la falta de estudios globales o parciales, 1levados a cabo con métodos y datos homogéneos que permitan comparaciones entre casos, a veces dispares en su naturaleza.

En virtud de lo anteriormente expuesto, el objetivo del presente trabajo consiste en aportar conocimiento acerca de los procesos de cambio de las ciudades intermedias. Más exactamente se trata de dar cuenta de las transformaciones socioespaciales en el contexto de los procesos mundiales antes nombrados, evaluando además la influencia del medio natural en la articulación del tejido físico y social de la ciudad. Esto último, de acuerdo con niveles de vulnerabilidad frente a riesgos naturales recurrentes y no recurrentes.

La hipótesis básica que subyace en este trabajo admite que en las ciudades de tamaño medio se reproducen, en general, procesos idénticos a los que operan en las grandes ciudades. No obstante las diferencias considerables de tamaño entre aquéllas y éstas, hacen que las modalidades y escala de los cambios sean distintas, no sólo en su extensión, sino también en la esencia. 
El área de estudio es la ciudad de La Serena, capital de la Región IV de Coquimbo, entidad emplazada en la región centro norte del país. Ésta ha mostrado una dinámica demográfica que en nada difiere del comportamiento que actualmente se le reconoce a las ciudades secundarias de los sistemas nacionales de asentamientos, puesto que sus tasas de crecimiento poblacional son más altas que las de las grandes ciudades y el incremento absoluto de la población urbana es considerable.

\section{MATERIALES Y MÉTODOS}

Uno de los procesos característicos que se da modernamente en las grandes entidades urbanas, es el paso de una ciudad compacta de alta densidad poblacional a una ciudad dispersa y fragmentada. Este tipo de estructura territorial, ha sido denominada por algunos investigadores nuevas periferias ( $\mathrm{Ej}$. MONCLÚS (1998) o metropolización expandida (DE MATTOS 1999); deriva de la dinámica de la suburbanización o periurbanización a que se ven enfrentadas la mayoría de las ciudades de carácter metropolitano.

Para DEMATTEIS (1998), la fragmentación de la ciudad no es nada más que el producto del ciclo urbano por el que transitan los grandes asentamientos humanos. Éste se inicia con la concentración de la población en el núcleo central o core (urbanización), prosigue con el crecimiento de las coronas o rings (suburbanización) y pasa luego al declive demográfico (desurbanización), en espera de una hipotética recuperación del núcleo central (reurbanización). En este mismo orden de ideas, FISHER (2003) en un estudio acerca del caso de las ciudades australianas, sugiere que el crecimiento periurbano representa los efectos combinados de cuatro procesos de migración de naturaleza compleja y que denomina de suburbanización, contraurbanización, retención de la población y migración centrípeta.

La dispersión urbana (urban sprawl), el modo de producción de los nuevos fragmentos ur- banos, así como sus modelos socioespaciales, morfológicos y funcionales asociados, muestran una ruptura con el espacio urbano preexistente. Algunas de las características de estas periferias son casi universales y se repiten en grandes y medianas ciudades americanas, europeas y asiáticas (THUILLIER 2001; PRÉVÔT 1999), donde se puede anotar algunas características:

- Predominan las formas de ocupación residencial extensivas, en áreas abiertas o en condominios (urbanizaciones cerradas). Estas se ubican en lugares bien comunicados, aunque separados del tejido principal, y con alta calidad de los valores ambientales del entorno. Estas tipologías se relacionan, en parte, con prácticas de promoción inmobiliaria que, entre otras consecuencias, fomentan la segregación, mediante la inserción diferencial en el nuevo espacio urbano en función de los niveles de renta.

- El sistema general de centralidades se reorganiza, debido a la emergencia de "centralidades inversas" en la periferia, cuyos polos son los centros comerciales (mall) y los servicios del alto rango (colegios, centros médicos, etc.).

- Se revaloriza la importancia estratégica de las infraestructuras de transportes y comunicaciones. Las nuevas necesidades de movilidad suelen saturar los sistemas existentes, por lo que es necesaria su modernización y reordenación. La accesibilidad del suelo es una cualidad esencial para determinar su valor, por lo que a la segregación física se une la social.

La convergencia de estos y otros factores ha dado lugar a un proceso general de reestructuración socioespacial y funcional que afecta a toda la ciudad. La disgregación periférica incrementa la ineficiencia al separar los lugares de residencia, trabajo, ocio y compra y encarece el costo de la infraestructura y equipamiento. Por otro lado, el espacio público de relación está prácticamente ausente de los nuevos desarrollos urbanos, donde es 
sustituido, para estos fines de sociabilidad, por espacios privados de acceso público (CAPRON 2002), sobre todo por los centros comerciales.

El centro histórico de la ciudad ha iniciado su declive demográfico y también experimenta la competencia funcional periurbana, aunque permanece como espacio simbólico principal. En resumen, parece que se ha consolidado ya un proceso que tiende más a la segregación socioespacial que a la integración, a la especialización más que a la multifuncionalidad, a la expansión más que a la reorganización. Al respecto POWER (2001), relacionando la exclusión social con dispersión urbana, da cuenta de los principales impactos ambientales, sociales, económicos y de la declinación que se originan al interior de las ciudades a causa de la dispersión suburbana. Entre los efectos ambientales, menciona el incremento de la contaminación atmosférica, del consumo y emisiones de energía, el impacto sobre el agua y uso del suelo, el aumento del ruido y la pérdida de tranquilidad.

El crecimiento disperso y poco denso puede desencadenar múltiples efectos negativos. En primer lugar y como se señalara con anterioridad, se desajusta la posible coherencia localizacional entre la residencia, el trabajo y los servicios. La ubicación periférica de la residencia y de los grandes centros de servicios multiplica los desplazamientos, congestionando las vías de circulación y siendo necesaria la creación de nuevas autovías urbanas y cinturones de circunvalación. Por otro lado, la baja densidad encarece el mantenimiento de los servicios públicos - por ejemplo, de transporte - y hace difícil la instalación de otros privados. Este inconveniente se agrava por las tipologías, muy extendidas, en urbanización cerrada.

Otro tipo de consecuencias, es el abandono del centro de la ciudad y de las áreas más viejas de los barrios, etapa inicial de procesos de segregación y especialización, que se oponen a los principios de continuidad y di- versidad del tejido físico y social, aportando a la ciudad dinamismo, vitalidad y eficiencia desde el punto de vista ambiental.

La segregación se ve reflejada en la inserción de los inmigrantes en las nuevas áreas periféricas, la que se produce de acuerdo a su capacidad económica, al tiempo que la ocupación del suelo en lotes homogéneos favorece la especialización de los usos. Estas características subrayan la tendencia hacia una ciudad extremadamente segregada y dividida.

En este sentido y de acuerdo a BORSDORF (2002), la segregación debe repensarse bajo la influencia de la globalización. La economía globalizada estimula procesos de una transformación profunda en el espacio urbano. El repliegue del Estado en cuanto a las políticas de vivienda, ha provocado procesos de desregulación (dependiendo cada vez más de mecanismos del mercado). También hay que considerar la influencia de la cultura globalizada, estándares universales y modas arquitectónicas (shopping centers, cadenas de fast food, parques de aventuras, hoteles, entre otros), que son promocionados y transmitidos por la telecomunicación.

\section{¿Ciudad compacta, ciudad dispersa?}

Uno de los asuntos más relevantes que se referencia hoy en día en la literatura para la planificación de las ciudades, es el de la forma urbana y su relación con la sustentabilidad. Las posturas se alinean en torno a los modelos opuestos de ciudad compacta y ciudad dispersa, siendo el primero, aunque no en estado puro, el que concita más consenso en cuanto a su mayor viabilidad ambiental (BREHENY 1992; BLOWERS 1993; JENKS et al. 1996).

Al respecto, autores como MCLAREN (1992) y NEWMAN (1992), en sus proposiciones a favor de la llamada ciudad compacta, se centran en el rol de las altas densidades como una herramienta para reducir las necesidades de viajes. Las ciudades dispersas son 
esencialmente dependientes del automóvil, en cambio las ciudades compactas, si bien es cierto que no necesariamente utilizan menos el auto, son menos dependientes, generando por lo tanto beneficios en la economía urbana y el ambiente. Densidad demográfica y uso del automóvil se encuentran altamente relacionados. Por su parte, la densidad y el uso del suelo son también variables relacionadas, pudiendo ser afectadas por el nivel y localización de la infraestructura caminera.

En esta misma línea se puede señalar que las variables claves que determinan la movilidad en las ciudades son densidad, grado de centralización y tamaño del asentamiento. Patrones dispersos y de baja densidad son la antítesis de lo que se requiere para disminuir los traslados en distancia y tiempo.

\section{Procedimientos}

Los procedimientos utilizados para la consecución de los objetivos del estudio fueron los siguientes:

- Para el análisis de la densidad de la población se utilizó el procedimiento estimador kernel, método que elude los sesgos producidos por las diferencias del tamaño y forma de las unidades geográficas, y otorga cierta continuidad espacial a la densidad. En este estudio se calculó la población en 107 puntos de la ciudad a partir de la suma de la población de las manzanas adyacentes (entre 4 y 8 ). Los valores de población de estos puntos se suavizaron con un kernel circular de 500 $\mathrm{m}$ de radio, es decir de una superficie de 78 ha. Esta distancia se justifica por ser muy cercana al recorrido medio urbano a pie que se realiza en 5 minutos, tiempo habitual de desplazamiento para adquirir bienes y servicios cotidianos.

- Respecto a la caracterización del espacio social de la ciudad se consideró la variable status ocupacional de la población migrante, que se trabajó a un nivel de resolución espacial de zonas urbanas de acuerdo con los índices de disimilitud de
Duncan y el índice $\mathrm{P}$ de Lieberson, utilizados habitualmente para medir la segregación socioespacial (SCHNELL \& OSTENDORF 2002). Los mismos datos se han clasificado mediante un procedimiento cluster y se les aplicó un análisis factorial para su reducción.

- En cuanto a la detección de amenazas naturales, éstas fueron abordadas desde el punto de vista del análisis de la vulnerabilidad, entendida como la predisposición o susceptibilidad que tiene un elemento a ser afectado o a sufrir una pérdida. Por lo tanto, y de acuerdo con MASKREY (1993), la diferencia de vulnerabilidad de los elementos determina el carácter selectivo de la severidad de los efectos de un evento externo sobre los mismos.

- Para el análisis de la vulnerabilidad sísmica se consideró la microzonificación realizada por THOMAS (1980) quien efectuó un estudio para predecir cuáles serían las probables diferencias de intensidad de los sismos en distintos lugares de la ciudad.

- Para el análisis del área posible de ser afectada por tsunamis, se utilizó el estudio de CASTRO et al. (2002) basado en la determinación de la cota de inundación a partir del uso de la ecuación de LAMB sobre el coeficiente de transmisión de energía (LAGOS 1997).

- Se definió además el nivel de vulnerabilidad socioeconómica para cada área de expansión. Este tipo de vulnerabilidad se refiere a la población e infraestructura expuesta y la propensión a sufrir un determinado nivel de pérdidas. En este sentido, las variables consideradas fueron la densidad, la repartición espacial de los tipos de población (según niveles socioeconómicos) y el material de las viviendas.

Es importante señalar que la noción de riesgo social ha atraído la atención dentro de la literatura académica (BECK 1992; 
GIDDENS 1990), siendo la conceptualización de estos fenómenos materia de considerable debate. En este contexto, resulta básico definir no sólo a qué fenómenos naturales está expuesto determinado lugar sino que también adquiere relevancia analizar la vulnerabilidad de la población, esperándose que una población con mejor nivel socioeconómico se encuentre más preparada para prevenir y enfrentar situaciones de emergencia.

En el presente estudio la evaluación de la vulnerabilidad global (niveles de vulnerabilidad físico-natural + niveles de vulnerabilidad socioeconómica) ha sido realizada mediante la metodología multicriterio, Proceso de Análisis Jerárquico (AHP), de SAATY (1997).

\section{RESULTADOS}

\section{La expansión urbana reciente: fragmentación física y dispersión periférica:}

Los principales procesos de reorganización urbana reciente aparecen asociados a las modalidades y magnitud del crecimiento del espacio urbano. Importante es destacar la influencia del medio físico en la articulación de la trama urbana e, indirectamente, también en la sociogeografía de la ciudad. Por otra parte, la evolución de la población, la relocalización de actividades creadoras de centralidad, así como las formas y tipologías de producción de los nuevos fragmentos de la ciudad, son los principales factores inmediatos responsables del nuevo modelo urbano en proceso de formación.

En el caso de La Serena, la configuración física del entorno ha orientado las direcciones de la expansión urbana y la disposición espacial de las diferentes partes de la ciudad, al tiempo que ha podido caracterizar determinados aspectos de su morfología (Fig. 1).

El rasgo más sobresaliente lo constituye la presencia de terrazas marinas que se desarrollan, en forma escalonada, paralelas a la costa de la bahía de Coquimbo: forman un anfiteatro frente al mar resguardado en parte por el Cerro Grande (Fig. 6). Su topografía plana las convierte en las áreas más atractivas para recibir el crecimiento urbano reciente. En la terraza más baja, continuación topográfica de la playa, se localizan los principales desarrollos urbanísticos ligados a las actividades de ocio y turismo. Al respecto COLES et. al. (2000) señalan que la colonización de áreas peligrosas, sobre todo de áreas costeras, ha conducido al incremento de la migración de familias de altos ingresos a estos lugares, en la búsqueda de belleza escénica, generando con ello un aumento en los valores de los seguros otorgados para propiedades costeras.

Sin embargo, en la actualidad la expansión urbana se ha orientado hacia las espaldas de la línea de costa, especialmente al sector de Cerro Grande, localizado al suroriente de la ciudad de La Serena. Este sector se ha constituido en la expresión concreta de un inicial proceso de dispersión urbana, patrón espacial característico de las grandes ciudades.

Otros elementos hidrográficos o topográficos se convierten en obstáculos de diverso tipo, destacándose el río Elqui, cuyo amplio cauce fragmenta la ciudad y reduce las posibilidades de comunicación; asimismo las fuertes pendientes de los escarpes de algunos talwegs y de cerros menores, limitan el crecimiento o favorecen la localización de determinados asentamientos marginales.

Finalmente, la actividad sísmica y la mala calidad geotectónica de los suelos de las terrazas marinas y fluviales bajas, deberían restringir la construcción en altura en estas zonas. Debe señalarse que la mayor parte de la superficie construida se encuentra por debajo de los $75 \mathrm{~m}$; por encima de esta altitud, hasta los $125 \mathrm{~m}$ se halla parte del barrio Las Compañías (Fig. 4) y la franja este de la ciudad, desarrollada en el piedemonte del Cerro Grande. Las pendientes son planas, casi siempre inferiores al 5\%; las máximas, aproximadamente entre el 10 y $14 \%$, aparecen en los 
Invest. Geogr. Chile, 36 (2002)
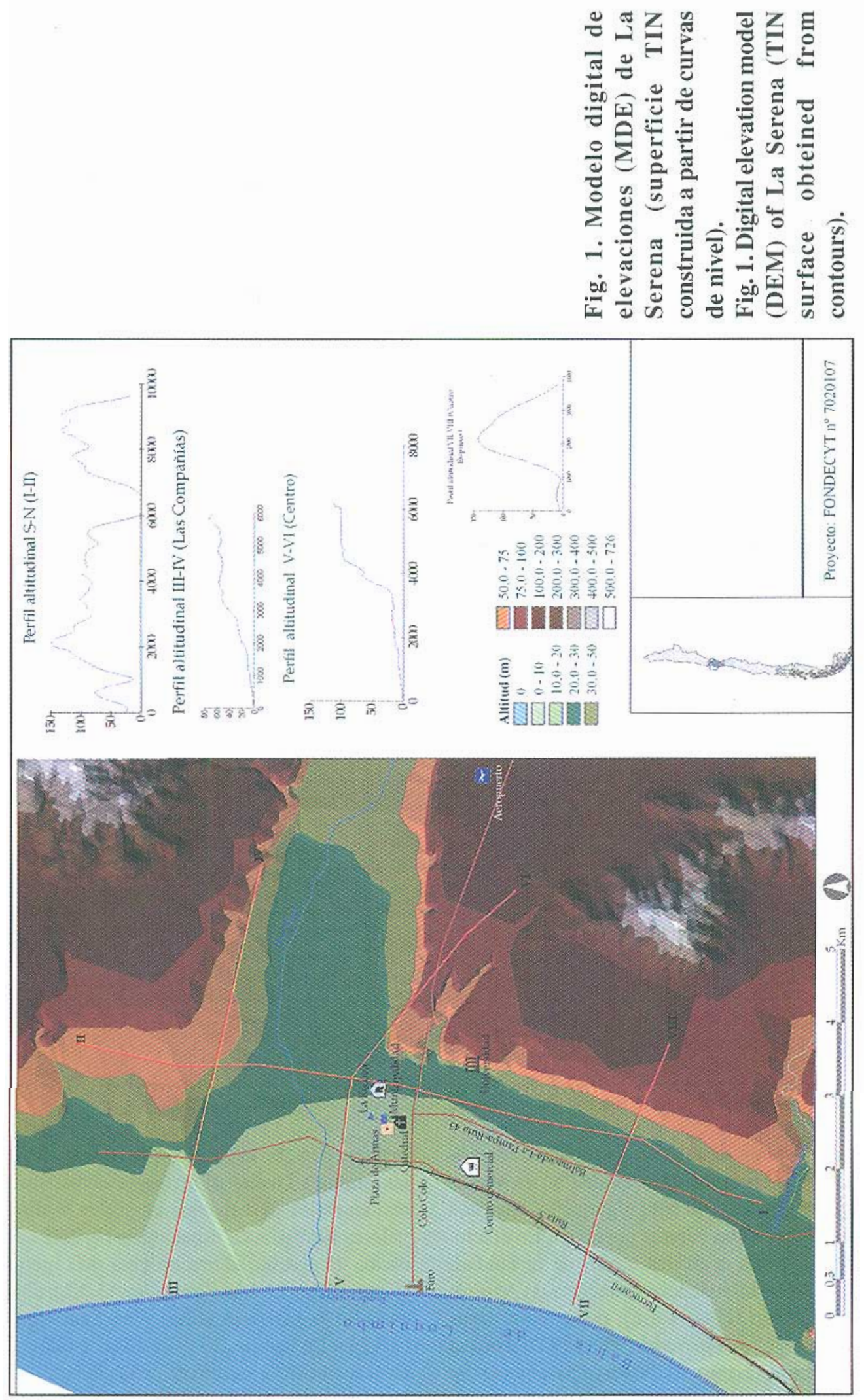
escarpes de las terrazas del Elqui y del talweg del estero Peñuelas (Fig. 3), y en las laderas del Cerro Grande (Fig. 6).

\section{Dinámica demográfica y redistribución espacial de la población}

Según resultados del último censo de población (2002), la tasa de crecimiento anual de La Serena alcanzó al 2,8\%, valor muy por encima del 1,2\% del país y del 1,3\% del Gran Santiago. Esta supremacía comenzó a manifestarse a partir de la década de los 80 del siglo recién pasado, al incrementarse sostenidamente la tasa de crecimiento demográfica en los sucesivos censos, y por el contrario, al disminuir sistemáticamente las tasas del país y la capital nacional.

En el contexto regional (Tabla 1) La Serena muestra, desde mediados del último siglo, pautas similares a las de la región, pero con tasas de crecimiento superiores. Desde las últimas décadas de siglo $\mathrm{XX}$, las tasas de crecimiento manifiestan una tendencia al alza que, en términos de valores absolutos, muestra que en los últimos 50 años la población se ha triplicado.

\section{Tabla 1: Evolución de la población de La Serena y de la Región de Coquimbo. 1920-2002}

Table 1: Evolution of the Population (1920-2002)

\begin{tabular}{|c|c|c|c|c|c|c|}
\hline \multicolumn{4}{|c|}{ Evolución de la población } & \multicolumn{3}{|c|}{ Tasa de crecimiento constante $(r \%)$} \\
\hline Año & La Serena & Región IV & \% IV Región & Período & La Serena & Región IV \\
\hline 1920 & 15.240 & 176.040 & 8,7 & & & \\
\hline 1930 & 20.698 & 198.336 & 10,4 & $1920-30$ & 1,6 & 1,2 \\
\hline 1940 & 21.742 & 245.609 & 8,9 & $1930-40$ & 0,9 & 2,2 \\
\hline 1952 & 33.785 & 262.120 & 12,9 & $1940-52$ & 2,3 & 0,8 \\
\hline 1960 & 40.854 & 308.991 & 13,2 & $1952-60$ & 2,6 & 2,1 \\
\hline 1970 & 61.897 & 340.215 & 18,2 & $1960-70$ & 2,3 & 0,9 \\
\hline 1982 & 83.238 & 419.956 & 19,8 & $1970-82$ & 2,3 & 1,7 \\
\hline 1992 & 109.293 & 504.387 & 21,7 & $1982-92$ & 2,4 . & 1,8 \\
\hline 2002 & 159.361 & 600.363 & 26,5 & $1992-02$ & 2,8 & 1,7 \\
\hline \multicolumn{7}{|c|}{$\begin{array}{l}\text { Tasa de crecimiento constante } r \%=(\text { raiz } t(P t+n / P t))-1 \\
P t+n \text { : población media de un periodo iniciado en el año } t \text { y de } n \text { años de duración } \\
N \text { : años transcurridos entre } t \text { y } t+n\end{array}$} \\
\hline
\end{tabular}

Fuente: INE "Población de los centros poblados de Chile. 1875-1992". Datos Preliminares Censo 2002.

No obstante lo anterior, la dinámica demográfica al interior de la ciudad no es homogénea, ya que son sólo algunos los distritos que crecen con valores positivos. En efecto, los distritos centrales (core) de la ciudad, como son Intendencia, Francisco de Aguirre y Mercado (Figs. 1 a 6), presentaron tasas negativas en el período 1982-1992 del orden de $-2.1 \%,-2.1 \%$ y $-0.7 \%$ respectivamente. Se muestra con ello el patrón típico que se da en las grandes ciudades, de bajas densidades residenciales en espacios centrales y altos valores positivos en espacios de periferia. A escala de distrito, el crecimiento más fuerte se manifiesta en Las Compañías (5.3\%), ubicado en la periferia norte, y en Las Vegas (3.5\%) y La Pampa (2.1\%), estos dos últimos en el sector sur y suroriente de la ciudad. 

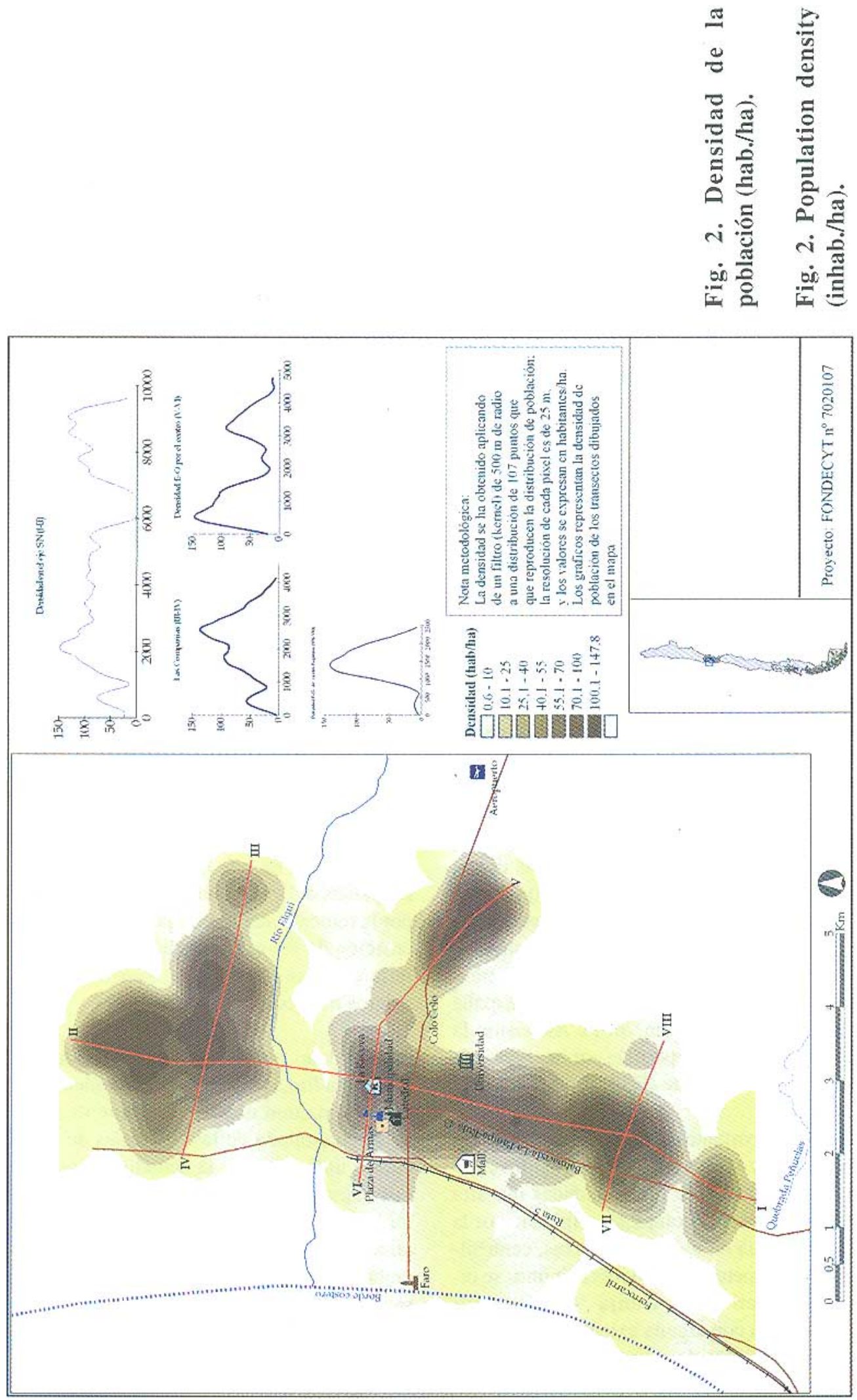
La disgregación del modelo de densidad

La densidad de población forma parte de todos los sistemas de indicadores sobre la ciudad, siendo el indicador por excelencia de la intensidad de ocupación del suelo, al tiempo que también se utiliza, entre otras funciones, para valorar la sustentabilidad de los modelos de crecimiento urbano. Al respecto, tuvo que obviarse las conocidas limitaciones del concepto "densidad", que derivan de los contenidos de las variables, de las unidades espaciales utilizadas y de la uniformidad implícita en el cociente de la ecuación de cálculo. Para ello, en el presente estudio se utilizó el método de estimación mediante filtros espaciales (kernel).

Conforme con patrón espacial resultante, la Fig. 2 confirma la inexorable marcha de la forma urbana de la ciudad de La Serena hacia la dispersión, en el sentido de dar cuenta del tránsito de una ciudad compacta de corte europeo hacia una ciudad difusa de tipo norteamericano (Fig. 9). Es así como frente a un esquema tradicional de la distribución de la densidad caracterizado por valores máximos en el centro histórico y que desciende hacia la periferia, el modelo actual es más complejo y polinuclear, organizado en torno a varias modas espaciales.

En general, se puede señalar que las densidades de población urbana son bajas, si se comparan con las de las ciudades europeas. Utilizando el mismo método, la densidad máxima de La Serena es de 148 habt./ha, frente a los 650 de habt./ha de Zaragoza, España (608.180 habitantes en 2001). Asimismo la distribución de la superficie por intervalos de densidad es diferente (ESCOLANO 2002).

Lo más importante son los cambios estructurales que se evidencian en la Fig. 2 . En efecto, la topografía de las densidades muestra una organización compleja, originada por la concurrencia de múltiples fuerzas, centrífugas y centrípetas. Los valores máximos se organizan en una franja longitudinal discontinua con alguna extensión lateral, siguiendo las vías de comunicación principa- les: arranca, por el norte, en el centro de Las Compañías (135 hab./ha), para proseguir, tras el vacío del cajón del Elqui, por el centro histórico (92 hab./ha), desde aquí se bifurca hacia el oriente siguiendo la vía hacia el interior del valle del Elqui y la ruta 41, donde se alcanza una de las cumbres de las densidades de La Serena (147 hab./ha); hacia el sur la cresta de máximos continua, más atenuada, por Balmaceda y la ruta 43, hasta la Av. de las Cuatro Esquinas, en el entorno de cuya intersección se encuentra otro máximo de densidades (148 hab./ha). Alrededor de esta espina dorsal las densidades descienden paulatinamente hacia la periferia, donde se localizan los valores más bajos.

En conjunto, el modelo se asimila a un esquema de orlas concéntricas entorno a varios núcleos principales separados por depresiones más o menos amplias. La planta no es circular, sino que se asemeja a una elipse desarrollada en sentido norte-sur y cuyo eje mayor se traza desde Las Compañías a través de Balmaceda hasta la Quebrada de Peñuelas, y el menor sigue la avenida Francisco de Aguirre y la vía hacia Vicuña (Figs. 1 a 6); el foco geométrico corresponde al centro histórico, que ya no presenta las densidades más elevadas.

La formación de este modelo se explica por las pautas del crecimiento urbano, así como por la relocalización de la población y por la creación de nuevas centralidades en la periferia (centros comerciales, supermercados, centros médicos, etc.).

Por otro lado, el espacio para uso residencial no es una función lineal del crecimiento demográfico, sino que la superficie de aquél depende también de las tipologías de edificación utilizadas. En la actualidad, los nuevos fragmentos se caracterizan por la uniformidad y banalidad del paisaje creado por alineaciones regulares y repetidas de casas unifamiliares aisladas o pareadas, o por la presencia de condominios, forma por excelencia de ocupación residencial intensiva del suelo (Fig. 10). Este patrón produce densi- 
Invest. Geogr. Chile, 36 (2002)
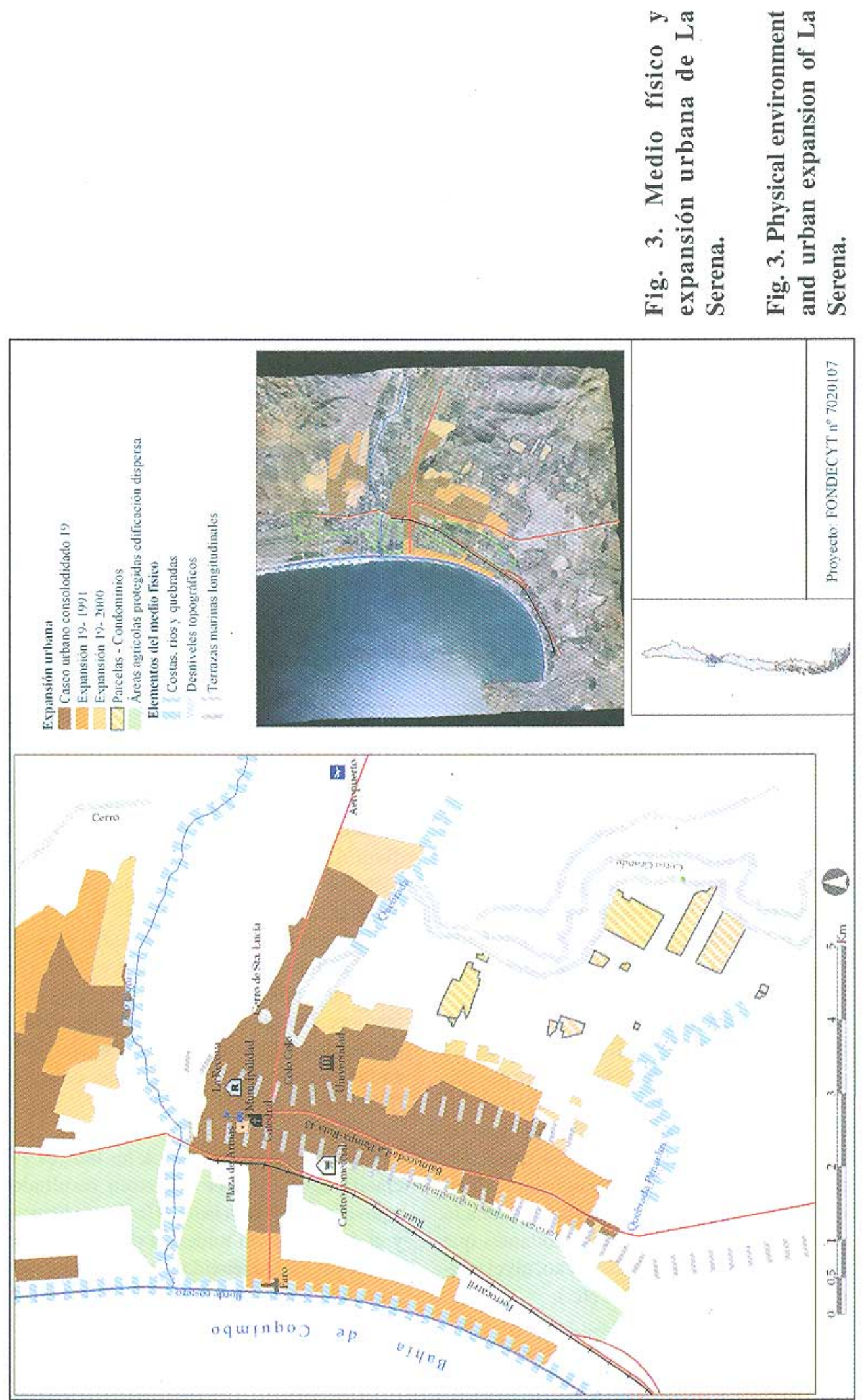
dades bajas y consume más suelo per capita (para viales, espacios privados, equipamientos), en buena parte de gran calidad agrícola.

Como se aprecia en la Fig 3, la expansión urbana reciente se ha producido desde el centro histórico y sus inmediaciones hacia el sur. La facilidad demográfica, la presencia de la ciudad de Coquimbo y las rutas 43 (Ovalle) y 5 (Panamericana), sobre las que se articulan las nuevas áreas, explican esta lógica. Es necesario añadir la función de ocio de la playa y de la franja costera, como factor de localización de las instalaciones turísticas, o la atracción de otros equipamientos importantes como la Universidad, así como la ruta hacia Vicuña (Av. Colo Colo), que han atraído el crecimiento de la ciudad hacia el este. El contexto detallado de los procesos de formación del espacio urbano y sus etapas se puede encontrar en VÉLIZ (1995). La clasificación realizada en este trabajo arroja los resultados que se resumen en la Tabla 2.

Tabla 2: Superficie ocupada por El desarrollo urbano reciente de La SERENa Table 2: Area Occupied by the recent uRban development of La Serena

\begin{tabular}{|c|c|}
\hline Clase & Superficie aproximada. (ha) \\
\hline Casco urbano & 1.091 \\
\hline Expansión hasta 1991 & 612 \\
\hline Expansión hasta 2000 & 382 \\
\hline Condominios & 130 \\
\hline Centro comercial & 18 \\
\hline
\end{tabular}

La inmigración urbana y aumento de la segregación socioespacial

Como se ha señalado, los modos de expansión urbana incrementan la movilidad espacial y la segregación social de la población. La inserción de los inmigrantes en las nuevas áreas periféricas se produce de acuerdo con su capacidad económica, al tiempo que la ocupación del suelo en lotes homogéneos favorece la especialización de los usos. Como bien señalan ORTIZ \& MORENO (2002), la intensificación de la segregación socioespacial tiene que ver con el direccionamiento de los desplazamientos de la población migrante, toda vez que estos movimientos en su mayor parte son realizados como un proceso selectivo, relacionado con las características de los habitantes que cambian de residencia (edad, sexo, nivel educativo, status ocupacional, etc.).

En tal sentido, y con el objeto de analizar el impacto de las migraciones en la sociogeografía de la ciudad, se procedió a establecer el patrón espacial de los inmigrantes por zonas según categorías de ocupación, mediante el cálculo del índice de disimilitud de Duncan y el índice $P$ de Lieberson. La finalidad de estos análisis es detectar las formas e intensidad de la segregación espacial de los inmigrantes y extender el estudio, en fases posteriores, a la relación con la política urbana, la pobreza y otros factores. Obviamente, los resultados son dependientes de las unidades espaciales utilizadas, en este caso, las zonas censales (BENESON \& OMER 2002).

Como se constata en la Fig 4, los índices y la clasificación cluster muestran resultados equivalentes. Por un lado, el índice de Duncan y el de Lieberson miden la disimilitud y el grado de heterogeneidad interna para cada zona. La diversificación mayor según el índice de Duncan corresponde a la zona 2 de Las Compañías, la más septentrional y a la zona 2 de Las Vegas. Si se aplica el índice de 
Invest. Gcogr. Chile, 36 (2002)
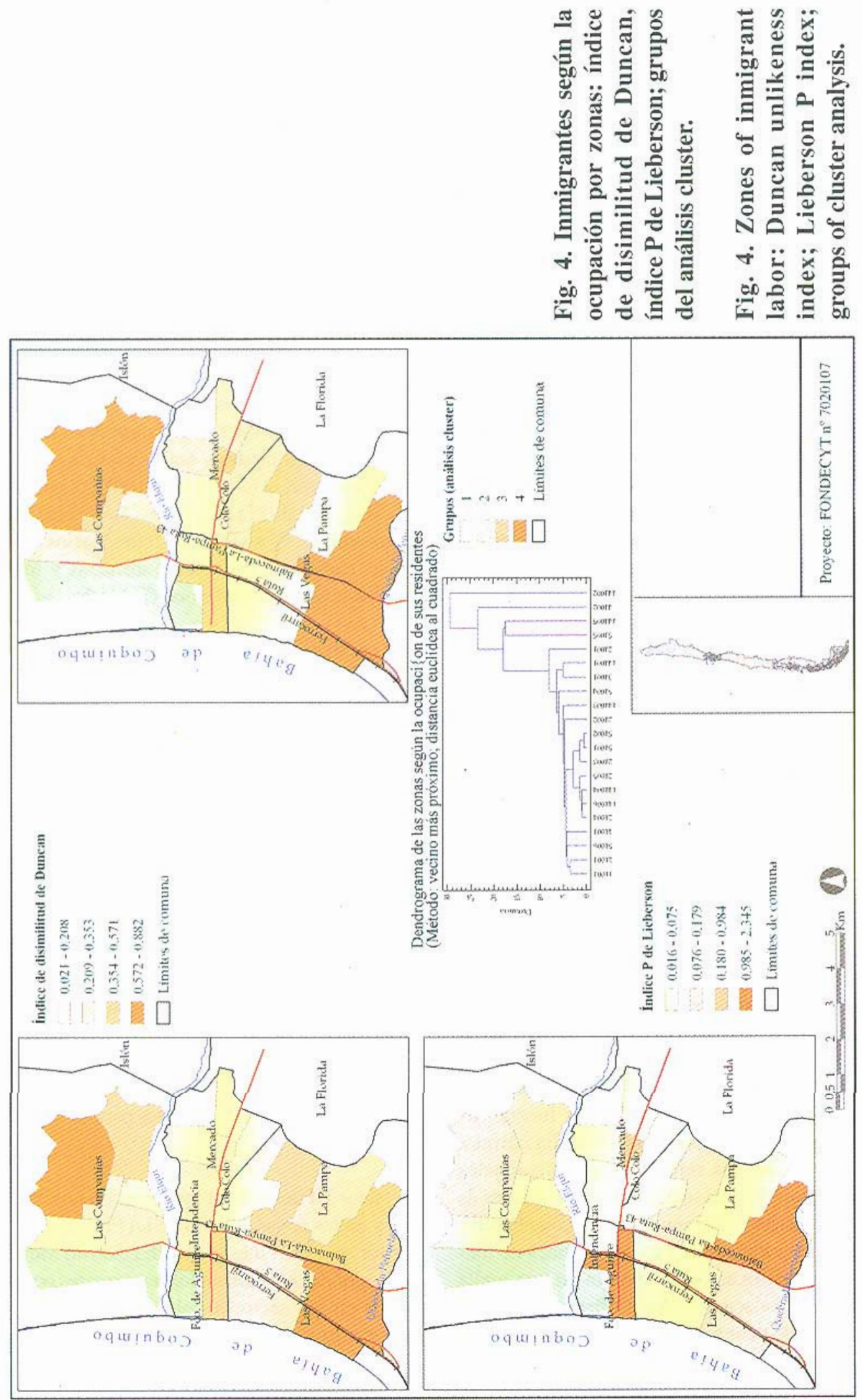
Lieberson la heterogeneidad mayor se encuentra en la zona 1 de Francisco de Aguirre y a la zona 5 de la Pampa.

Las zonas más homogéneas y menos diversas son las zonas 5, 3 y 4 del distrito Mercado, las zonas 4 y 6 de Las Compañías, la zona 1 y 2 de La Pampa. Esta mayor segregación procede de dos tendencias, hasta cierto punto contrapuestas: de la concentración de inmigrantes de ocupaciones de baja cualificación, o en el otro extremo de la acumulación en el espacio de profesionales muy cualificados.

Se ha utilizado un procedimiento de clasificación cluster para agrupar las zonas en clases (Fig 4). En el dendrograma se aprecia que las zonas más parecidas entre sí (grupo 1) son aquellas que tienen valores más bajos en los índices de Duncan y Lieberson, es decir, menos heterogenidad y por tanto mayor concentración y segregación de actividades. Los grupos 2 y 3 tienen valores de disimilitud y heterogeneidad medios, y también presentan bastante semejanza entre todas las zonas, pues las distancias entre ellos son pequeñas. Finalmente, el grupo 4 es el que se diferencia de los demás con mayor nitidez. Lo integran las zonas más heterogéneas y diversas, ubicadas en los extremos norte y sur de La Serena (aunque la similitud interzonas es menor que en los casos anteriores).

Los resultados del análisis factorial de los inmigrantes muestran asociaciones espaciales en las ocupaciones que corroboran y completan las medidas anteriores. En efecto, la correlación entre variables permite distinguir grupos de variables con asociación muy elevada. Las variables referentes a fuerzas armadas y poder ejecutivo tienen alta correlación mutua; las referentes a profesionales universitarios se asocian con profesionales de nivel medio y, en menor grado, con el sector del poder ejecutivo. Las profesiones de mediana cualificación se asocian en una malla densa de relaciones: los profesionales de nivel medio tienen alta conrelación con los sectores de empleados de oficina y servicios de venta; estos dos últimos se asocian con operadores de máquinas, que a su vez lo hacen con mecánicos y operarios. Las actividades de agricultura y pesca conectan con mecánicos y operarios y con operadores de máquinas y los sectores de profesiones no cualificadas con los de mecánicos y operarios.

Las variables en cuestión se fundieron en tres factores: el primero (factor I) se podría asimilar a las actividades de clases medias bajas y clases bajas (mecánicos y operarios, trabajadores no cualificados, operarios de máquinas y servicios de venta); el segundo (factor II) se asocia con actividades de tipo medio (clase media-media) y resume las actividades de nivel medio y empleados de oficina; finalmente, el tercero (factor III), condensa las actividades de las clases supraordinarias, a saber, los funcionarios del poder ejecutivo, las fuerzas armadas y los profesionales universitarios (Tabla 3).

Las puntuaciones (scores) de los factores en cada zona clarifican la naturaleza de la segregación socioespacial de la inmigración. El factor I tiene sus valores más altos en las zonas más septentrionales de Las Compañías, debido a la concentración de inmigrantes de media y baja cualificación, aunque la diversidad interna es bastante alta. Los más bajos se presentan en algunas zonas de Francisco de Aguirre y La Pampa. (Fig 5)

Los pesos del factor II son más fuertes en la zona de Francisco de Aguirre y en la zona 5 de La Pampa, debido a la concentración de empleados de oficina y profesionales de nivel medio y otras actividades relacionadas con éstas. Los valores más bajos aparecen en las zonas donde eran más altos para el factor I.

El factor III destaca en las zonas de Las Vegas y en las zonas 3, 4 y 6 de La Pampa y, en menor medida, en la zona 1 del distrito Mercado, donde se localizan los inmigrantes ocupados en los sectores del poder ejecutivo, fuerzas armadas y profesionales universitarios. 
Tabla 3: Matriz de componentes rotados

Table 3: Matrix of the rotated components

\begin{tabular}{|c|ccc|}
\hline Variables & \multicolumn{3}{|c|}{ Componente } \\
\hline & 1 & 2 & 3 \\
\hline Fuerzas armadas &, 155 &,- 036 &, 829 \\
\hline Poder ejecutivo &, 007 &, 191 &, 915 \\
\hline Profesores universitarios &,- 035 &, 555 &, 574 \\
\hline Profesionales nivel medio &, 250 &, 765 &, 348 \\
\hline Empleados de oficina &, 373 &, 805 &, 280 \\
\hline Servicios de venta &, 727 &, 540 &, 161 \\
\hline Agricultura y pesca &, 896 &, 000 &, 113 \\
\hline Mecánicos y operarios &, 957 &, 047 &,- 123 \\
\hline Operarios de máquinas &, 757 &, 496 &,- 071 \\
\hline Trabajadores no cualificados &, 686 &, 001 &, 306 \\
\hline No clasificados &,- 154 &, 673 &,- 354 \\
\hline
\end{tabular}

Método de extracción: análisis de componentes principales

Rotación: varimax con normalización Kaiser.

A modo de resumen, se puede afirmar que la segregación espacial de los inmigrantes según su ocupación se manifiesta por grupos de actividades. Las de baja cualificación (las asociadas al factor I) se concentran preferentemente en las zonas norte y sur de la ciudad, en relación con los precios más bajos del suelo y la cercanía de empleos industriales y agrarios; internamente, estas zonas presentan cierto grado de heterogeneidad. Las de cualificación media (relacionadas con el factor II) ocupan zonas del centro y sur de la ciudad, especialmente en el distrito Mercado, Francisco de Aguirre y la zona 5 de La Pampa. Finalmente, las ocupaciones de alta cualificación (expresadas en el factor III), presentan mayor segregación, pues se concentran casi exclusivamente en las zonas ya citadas de Las Vegas y La Pampa, que a su vez son las de menor diversidad interna.
Riesgos naturales y vulnerabilidad física y social

Dentro de los peligros naturales recurrentes analizados para el caso de La Serena las inundaciones tienen una mayor significación espacial, tanto las provocadas por desborde del río Elqui y esteros secundarios, como aquellas producidas por la acumulación de aguas lluvias y afloramiento de napas freáticas en áreas deprimidas (Fig. 6).

En general, las inundaciones son el resultado de causas naturales, antrópicas y una combinación entre ambás. En esta ciudad el problema de las inundaciones es significativo en las terrazas bajas, ya que la rápida urbanización gestada en las últimas décadas se ha producido sobre zonas pantanosas, donde la napa freática se encuentra muy próxima a la superficie, no existiendo condiciones adecua- 


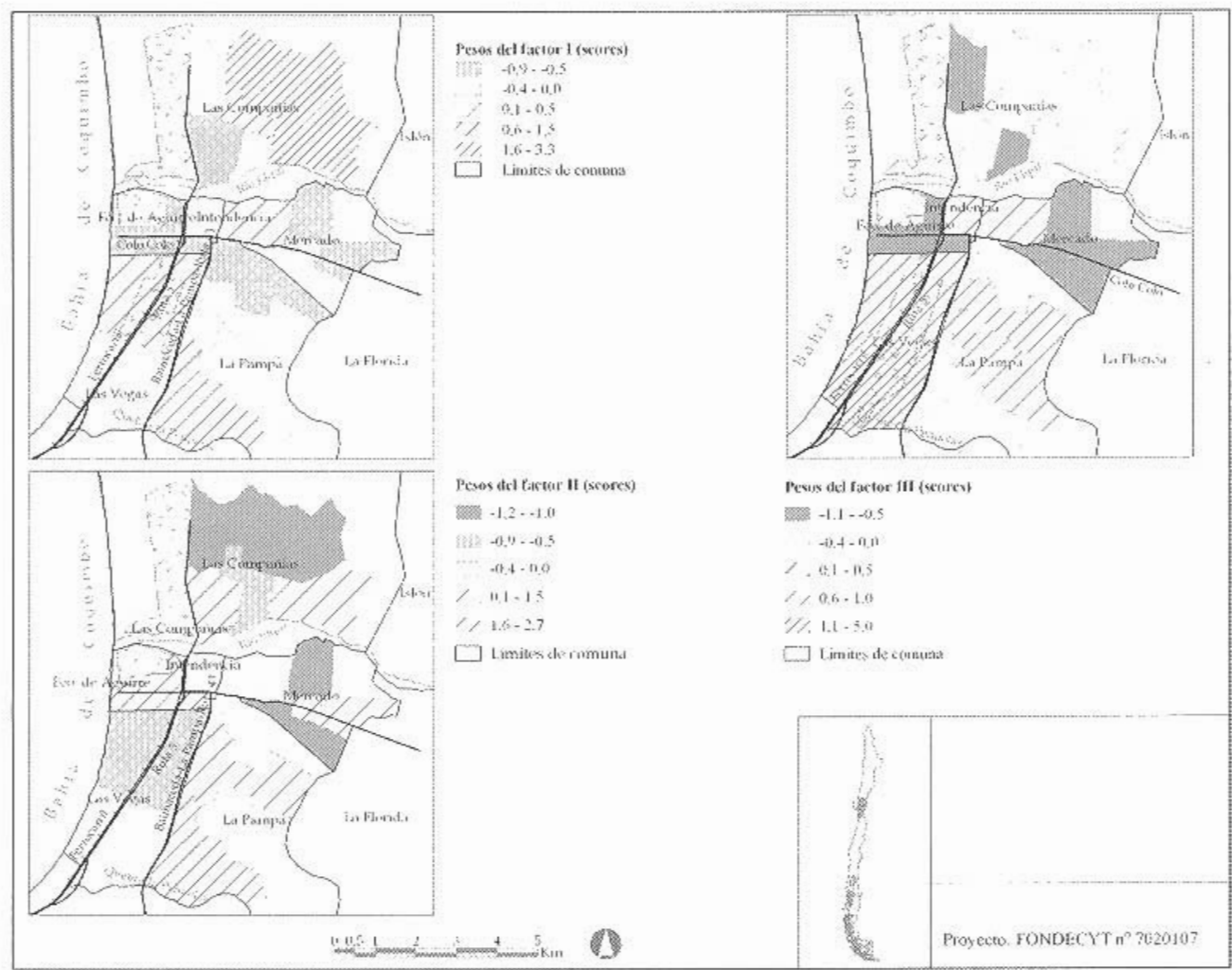

Fig. 5. Pesos de los factores en cada zona.

Fig. 5. Scores of factors for each zone.

das para el escurrimiento superficial de las aguas.

En cuanto a los peligros considerados como no recurrentes, estos corresponden principalmente a los movimientos sísmicos y a los tsunamis (Fig.7). Debe recordarse que La Serena está incluida en la zona definida por Labbé y Saragoni (THOMAS 1980), como de gran sismicidad $\left(26^{\circ} \mathrm{S}\right.$ a $\left.\operatorname{los} 36^{\circ} \mathrm{S}\right)$, caracterizada por sismos de foco poco profundo. Este autor señala que las ciudades de Coquimbo y La Serena han sido seriamente dañadas por terremotos por lo menos cinco veces.

\section{Clasificación espacial según grados de vulnerabilidad}

Se resume aquí los resultados obtenidos sobre la base del nivel de vulnerabilidad global de cada zona de expansión de la ciudad ante eventos de desastres. Se definió básicamente dos niveles de vulnerabilidad físico - natural para las áreas de expansión reciente de La Serena, las que tienen relación con su conformación geomorfológica y pedológica, y que presentan a su vez diferentes grados de vulnerabilidad social, lo que implica que tendrán un comportamiento disímil frente a un desastre natural (Fig 8).

\section{Areas de baja vulnerabilidad global}

Sector Universidad Este sector de expansión relativamente reciente presenta una baja exposición a los peligros naturales, encontrándose sólo algunos lugares puntuales donde se produce inundación por lluvias y socavamiento lateral de terrazas. Posee además, una baja vulnerabilidad a movimientos sísmicos caracterizándose por presentar sue- 


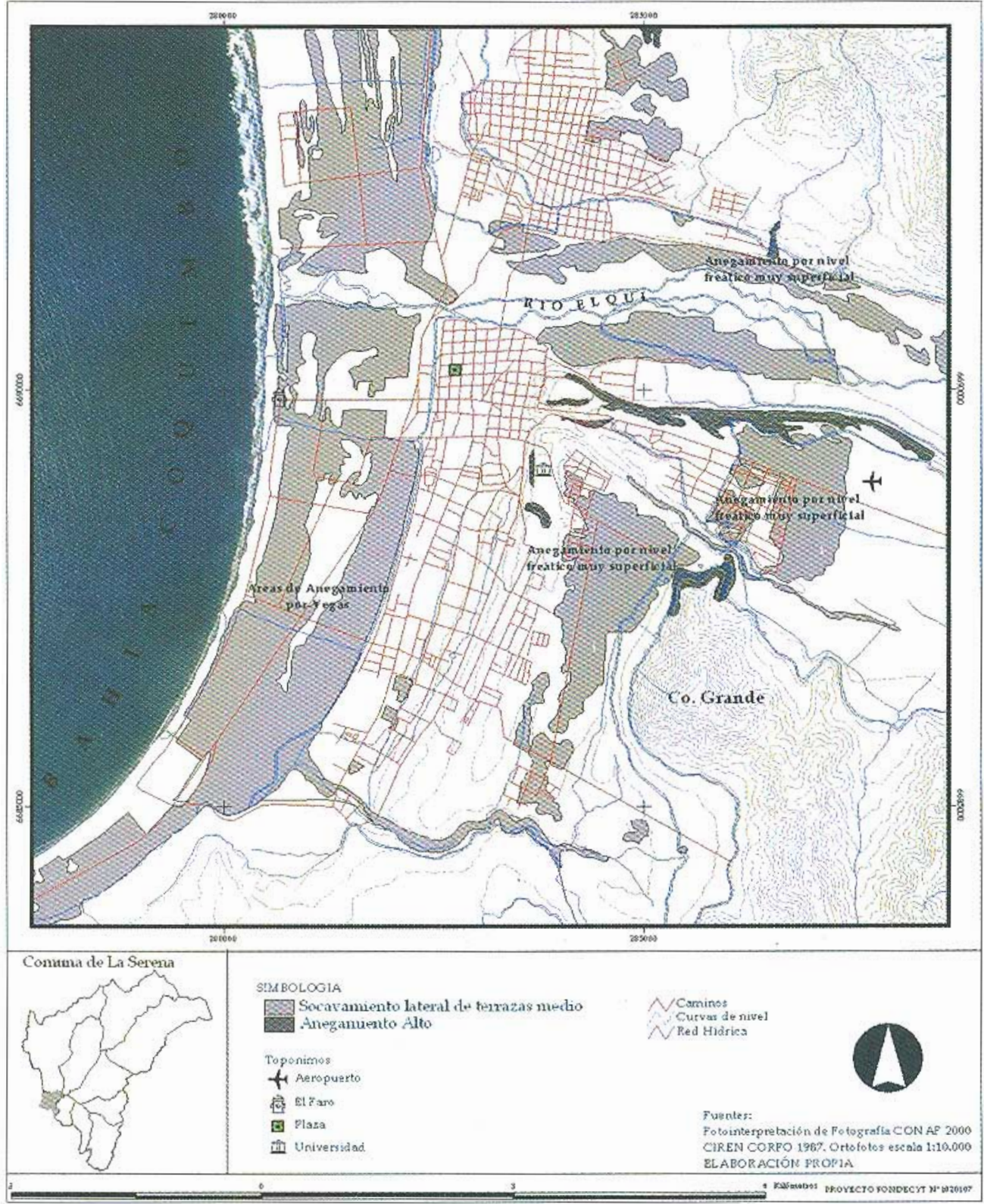

Fig. 6. Áreas de inundación y socavamiento lateral recurrente de terrazas.

Fig. 6. Areas of flood and lateral carving of terraces. 


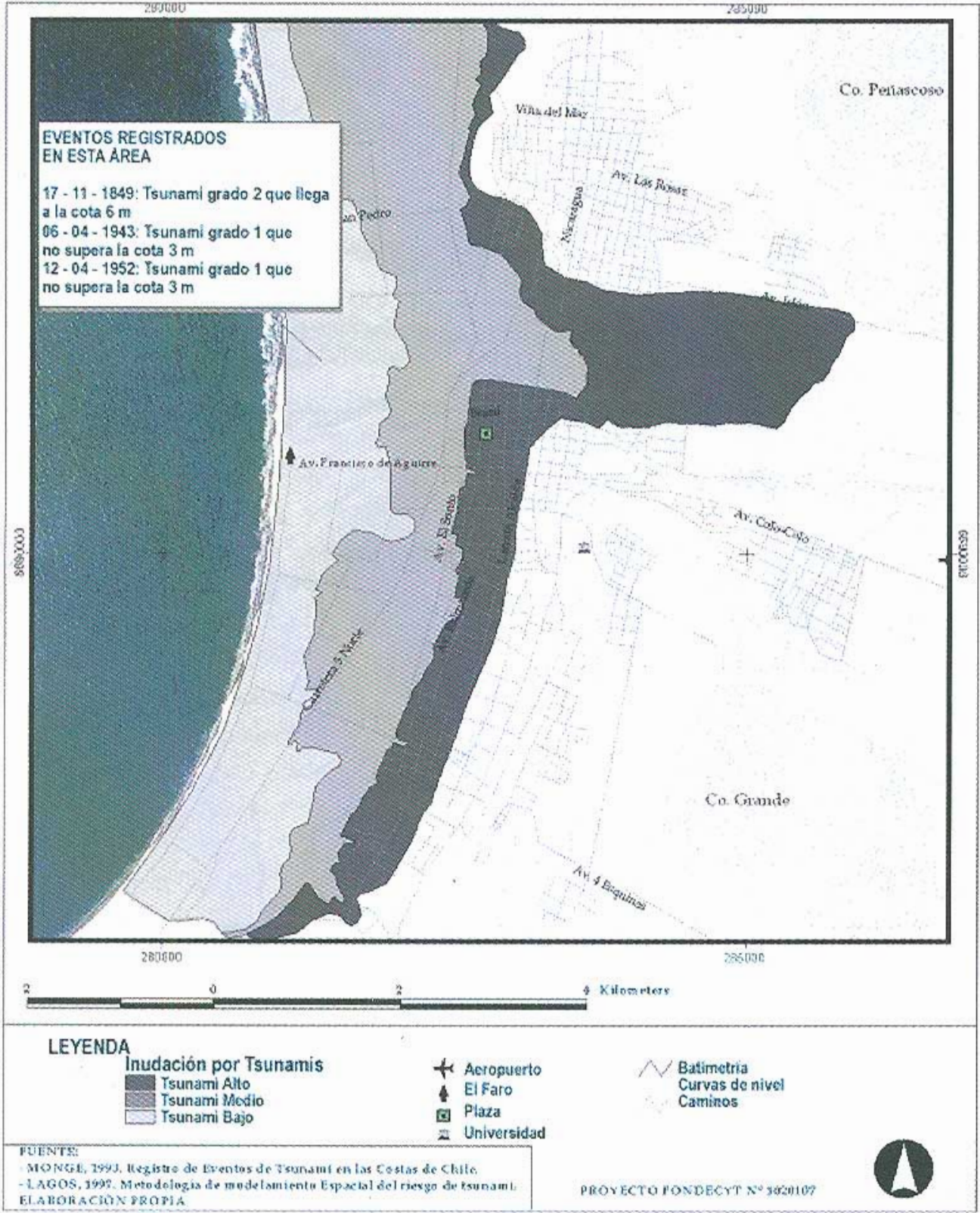

Fig. 7. Alturas de inundación alcanzadas por tsunamis.

\section{Fig. 7. Flood heights reached by tsunamis.}

los finos, franco arcillosos, de permeabilidad baja con un nivel freático muy profundo. Además, los sedimentos son de origen marino y fluvial, compactos y cementados y presentan por este motivo, una buena calidad geotectónica, que es mejor a medida que se alcanzan los niveles más altos de las terrazas (THOMAS, 1980). Es un sector de baja densidad de población y nivel socioeconómico medio - alto y alto, que le otorga por lo tanto una baja vulnerabilidad social. 


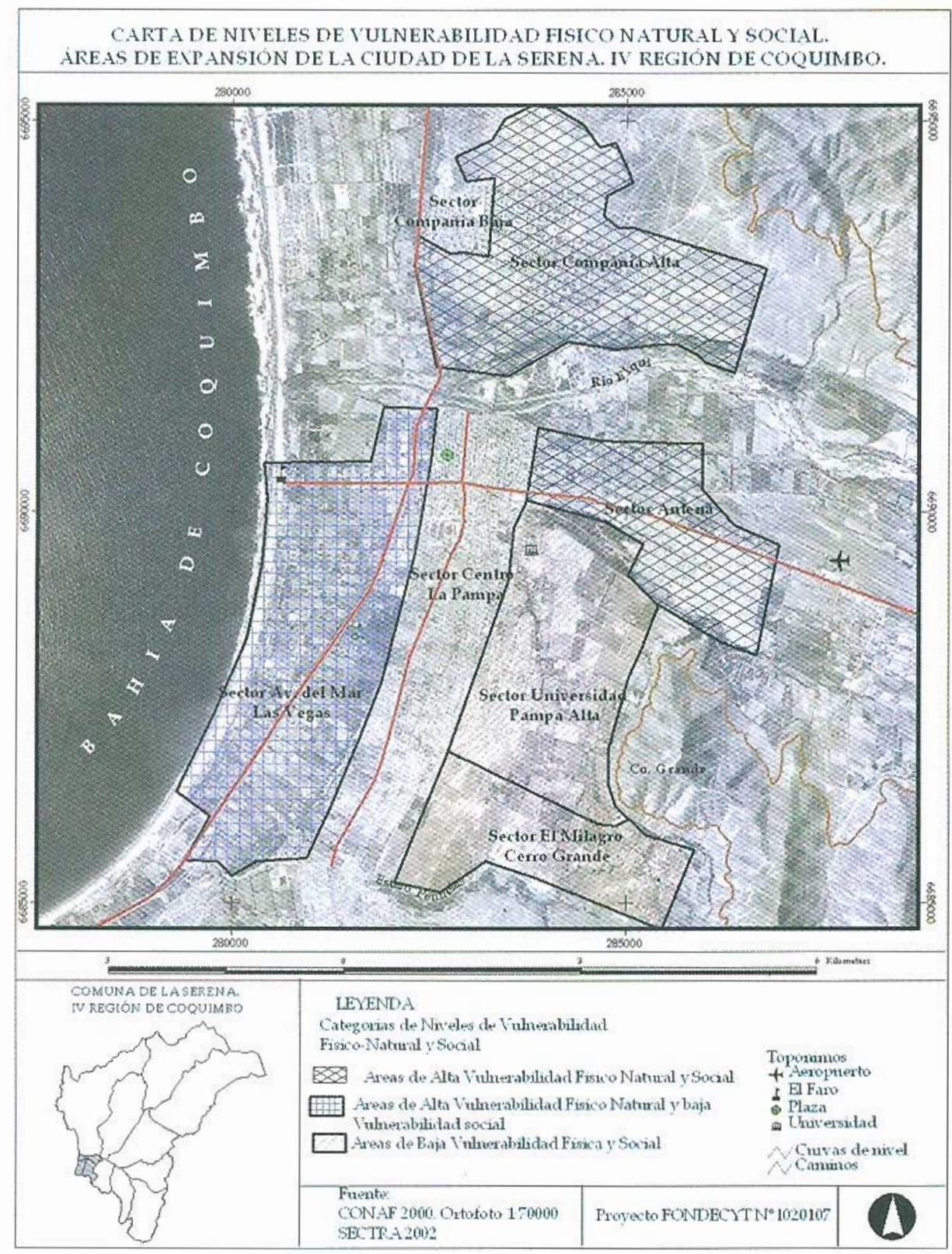

Fig. 8. Vulnerabilidad natural y social. Áreas de expansión de La Serena.

\section{Fig. 8. Natural and social vulnerability. Expansional areas of La Serena.}

Sector Cerro Grande - El Milagro Corresponde al sector de expansión más reciente. Presenta escasos peligros recurrentes, en sectores muy localizados afectos a inundaciones por lluvias. Esta zona presenta también una vulnerabilidad a la sismicidad, aunque muy localizada, en el área de conos coluviales, de suelos arcillosos finos y permeabilidad baja. Este cerro es parte de una aureola de rocas metamórficas formadas por los intrusivos cretácicos que intruyen las rocas preexistentes. Estas rocas de 


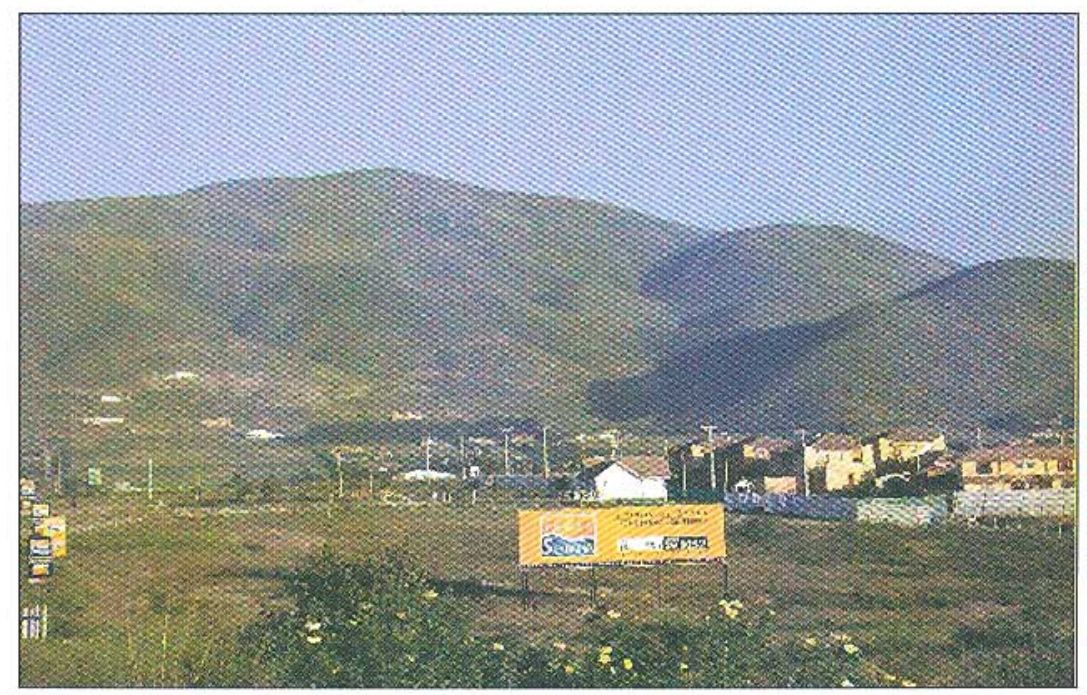

Fig. 9. Area de crecimiento residencial sector Los Milagros - Cerro Grande Fig. 9. Area of sprawl Los Milagros - Cerro Grande.

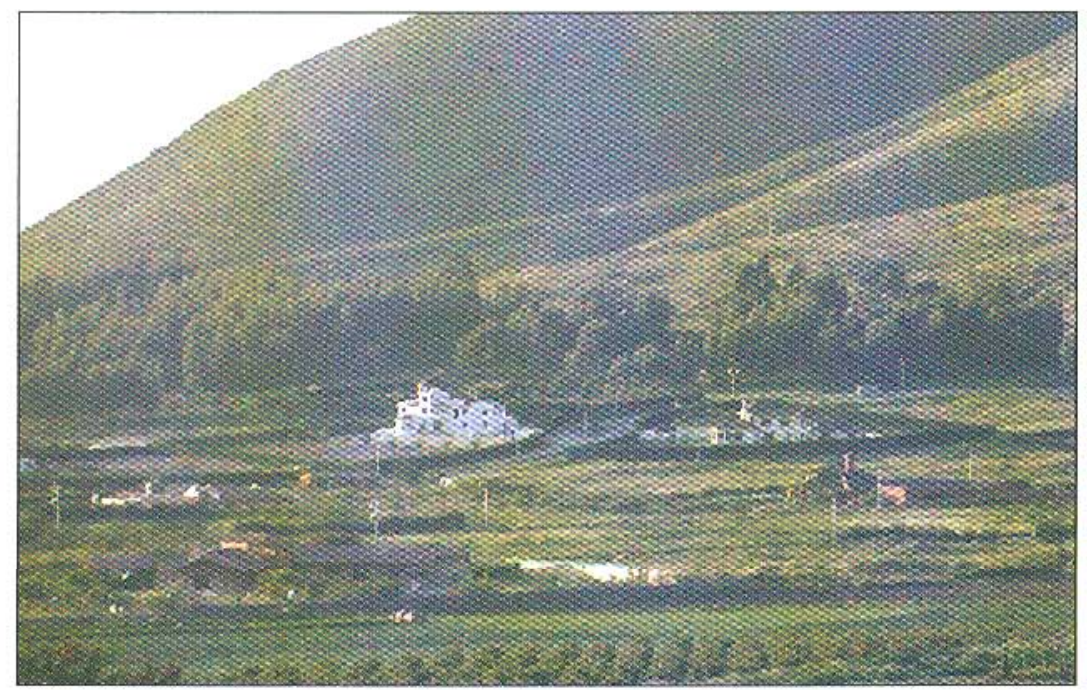

Fig. 10. Segregación social. Desarrollo de condominios sector Cerro Grande Fig. 10. Social segregation. Sector of gated communities in Cerro Grande 
metamorfismo de contacto poseen en general calidad geotectónica buena (THOMAS 1980), desde el punto de vista de la mecánica de suelos. En términos de vulnerabilidad social, ésta es poco considerable debido a la baja densidad poblacional y a que corresponde a un estrato socioeconómico medio alto y alto.

Areas de media a alta vulnerabilidad global Sector Compañía Alta Este sector representa la expansión de la ciudad entre 1980 y 2000 de un estrato socioeconómico medio - bajo. Se extiende en las diferentes terrazas al norte del río Elqui, lo que implica que su exposición a los peligros naturales no es homogénea. Ha sido calificado como de vulnerabilidad físico natural media a alta, debido a la recurrencia de fenómenos de inundación en el lecho mayor episódico y algunos sectores de inundación por aguas lluvias en la terraza alta principal. Las otras terrazas son menos vulnerables.

La terraza baja presenta la mayor vulnerabilidad a movimientos sísmicos debido al tipo de suelos de fundación, que corresponden a aquid camborthid, delgados, de textura franco arcillo arenosa y franco arcillo limosa, con drenaje imperfecto o impedido, permeabilidad baja y escurrimiento superficial lento a moderado. THOMAS (1980) señala que los sedimentos recientes asociados a cauces fluviales y las arenas de playas constituyen suelos de fundación deficientes o francamente malos ya que sus depósitos se encuentran casi siempre saturados y tienen escasa profundidad. Se caracterizan además por elevadas porosidades y permeabilidades y deficientes capacidades soportantes.

Se puede considerar entonces a Las Compañías como un área sujeta a riesgos recurrentes y no recurrentes, aunque estos últimos son más significativos. Con respecto a su vulnerabilidad social, ha sido calificada como alta, debido al bajo nivel socioeconómico de su población, la alta densidad y el predominio de viviendas de adobe (Fig. 11).

Sector Antena Es un sector vulnerable a peligros reçurrentes y no recurrentes. Presenta problemas relacionados a inundaciones por aguas lluvias y por desborde. Es además una zona medianamente vulnerable a movimientos sísmicos por poseer suelos franco arcillosos con problemas de drenaje.

\section{Vulnerabilidad global mixta}

Sector Avenida del Mar corresponde a un área de expansión urbana de las décadas de 1980 y 1990 que presenta una importante vulnerabilidad físico natural tanto a peligros recurrentes como no recurrentes, ya que puede ser afectada completamente por inundaciones y tsunamis. Por este motivo es considerada como la zona de La Serena más vulnerable a sismicidad; presenta además frecuentes problemas de inundación por lluvias y afloramiento de la napa freática. Los peligros más significativos en esta zona están asociados a la ocurrencia de tsunamis, de los cuales existen registros de tres eventos anteriores, con una cota máxima de inundación de $6 \mathrm{~m}$. La alta vulnerabilidad ante sismos está relacionada fundamentalmente con la mala calidad de los suelos de fundación, que son en general de la familia de los aquid camborthid, de textura fina, franco arcillo arenosa y con drenaje imperfecto (Fig. 12). THOMAS (1980) considera la posibilidad de ocurrencia de asentamientos importantes de las estructuras que se funden en esta zona, como también compactaciones o licuefacciones por efecto de las ondas sísmicas, además señala que los rellenos artificiales deben considerarse como de mala calidad geotectónica. Estos rellenos son una práctica común actualmente en esta zona y se efectúan por iniciativas particulares, lo que ha provocado en muchos casos, un empeoramiento en las condiciones de inundación de los sectores vecinos. El estudio de este autor concluye que esta zona no es recomendable para la construcción de viviendas y estructuras complejas, y debería destinarse a terrenos de cultivo y áreas verdes. Señala que en general debe evitarse el crecimiento de poblaciones hacia las partes bajas de la ciudad y una eventual expansión del límite urbano deberá realizarse hacia los sectores altos, que es lo que espontáneamente está sucediendo actualmente. 


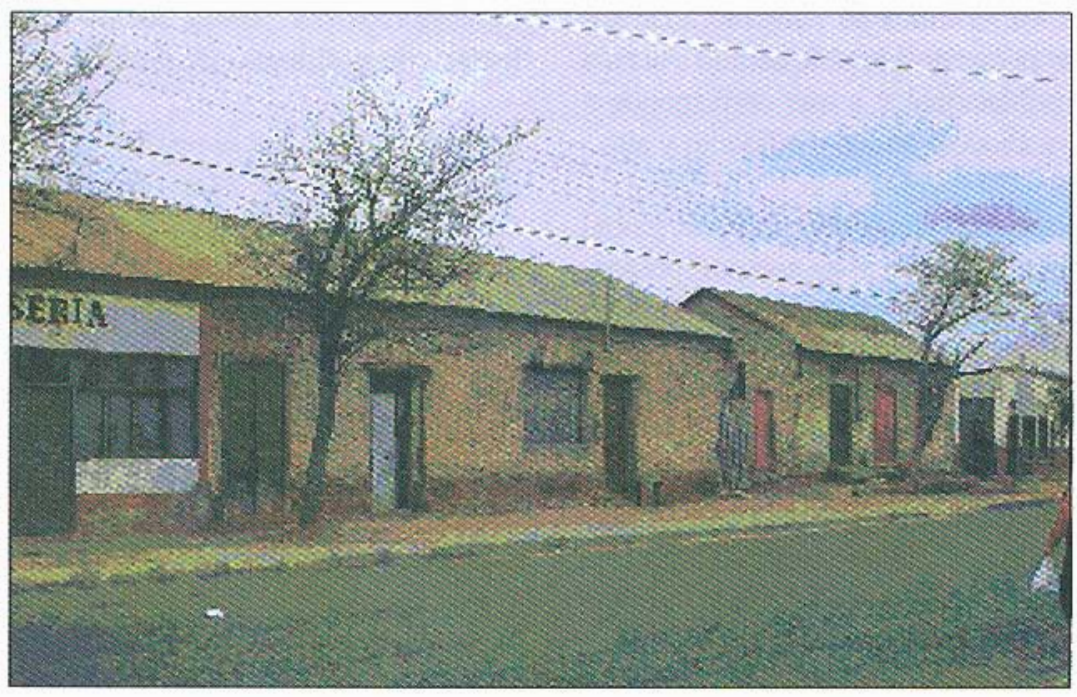

Fig.11. Sector Las Compañías. Dominio de las viviendas de adobe Fig. 11. Las Compañías. Adobe houses.

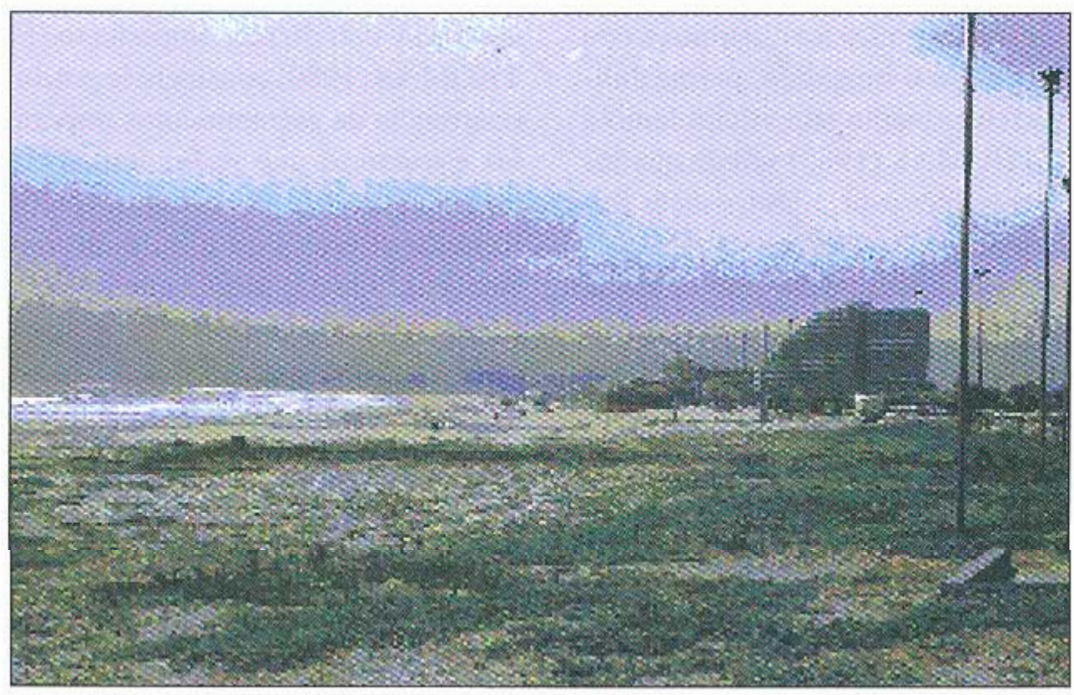

Fig. 12. Sector Avenida del Mar. Desarrollo inmobiliario asociado al turismo Fig. 12. Avenida del Mar. Buildings of coastal tourist sector. 
No obstante, el sector Avenida del Mar, de importante vulnerabilidad físico natural, presenta una baja vulnerabilidad social debido a que corresponde a un estrato socioeconómico medio - alto y alto con una baja densidad poblacional.

\section{DISCUSIÓN}

Se puede afirmar que, en general, que se valida la hipótesis subyacente de este estudio: las ciudades medianas, como es el caso de La Serena, reproducen procesos funcionales y socioespaciales que normalmente se dan en las ciudades de carácter metropolitano.

Al notable crecimiento demográfico de la capital regional se suma el evidente proceso de dispersión urbana que se desarrolla desde hace algún tiempo. La aparición de espacios cerrados (condominios) en territorios que perfectamente se pueden reconocer como de nuevas periferias, ha llevado a la ciudad a pasar de una morfología tradicionalmente compacta, a una ciudad dispersa y difusa. La suburbanización o periurbanización de estos espacios, se manifiesta con nitidez al oriente de la ciudad, donde también se han emplazados servicios de alto rango, tal como ha ocurrido con la presencia de establecimientos educacionales, entre otros.

La estructura funcional de la ciudad, además se ha visto modificada por la presencia de un gran centro comercial excéntrico ("mall"), el cual ha incidido, en cierta medida, en el debilitamiento de esta actividad económica que tradicionalmente ha estado presente en el centro de la ciudad.

En cuanto a la movilidad espacial de la población, los sectores al norte del río Elqui (distrito Las Compañía) y sur y sureste de la ciudad (distritos Las Vegas y La Pampa), se han constituido en los principales focos de atracción de los movimientos poblacionales, a diferencia de los espacios centrales, en donde los índices muestran valores negativos, pauta característica de las grandes ciudades. Además, los movimientos poblacionales han incrementado la complejidad de la estructu- ra socioespacial de la ciudad, en tanto que han contribuido a conformar nítidos patrones de segregación social.

Con respecto a los peligros naturales que se dan en la ciudad, se puede señalar que los de tipo recurrentes (inundaciones) son localizados, afectando a gran cantidad de población, aunque su impacto no tiene el mismo alcance espacial que se da en las ciudades de la zona central o sur del país. Sin embargo, su exposición a peligros no recurrentes (sismos y tsunamis) es significativa, principalmente en las zonas bajas de la ciudad.

En cuanto a la vulnerabilidad física y social, se observa que la localización de la población de menor status socioeconómico ha estado dirigida hacia los sectores más alejados del centro de la ciudad, como Las Compañías y Antena más recientemente (Fig. 8), constatándose que la media a alta vulnerabilidad social que las caracteriza no se asocia, como comúnmente sucede, con una exposición a los peligros naturales.

Una situación exactamente contraria se da en el sector Avenida del Mar, donde la población, ha valorado más las ventajas del litoral que los serios inconvenientes de las frecuentes inundaciones y el riesgo de sufrir eventos catastróficos asociados a sismos y tsunamis, permitiendo concluir que se tiene una muy baja percepción asociada a los peligros naturales no recurrentes y su significado real.

Sin embargo esta situación no es genérica, ya que actualmente se está produciendo un proceso de relocalización de la población de estratos medios a altos orientado hacia las espaldas de la línea de costa (sector Universidad y Cerro Grande), hecho claramente ligado a la valoración estética del entorno y a la baja vulnerabilidad a los peligros naturales de ambos lugares.

En síntesis, se puede señalar que el proceso de reestructuración urbana acaecida en la ciudad de La Serena en las dos últimas décadas ha evolucionado definitivamente hacia una estructura más dispersa y difusa, más segre- 
gada socialmente y consumidora de recursos de suelo y energía, generando un crecimiento que perfectamente se puede calificar como no sustentable, conforme a evidencias de otras realidades.

\section{REFERENCIAS}

BECK, U., 1992. Risk Society: Towards a new modernity. SAGE, London.

BENESON, I. \& I. OMER, 2002. Measuring individual segregation in space. A formal approach and case study. In: Schnell, I. \& W. Ostendorf (Eds.), Studies in segregation and desegregation. Ashgate, Aldershot, pp.11-38.

BLOWERS, A (Ed.), 1993. Planning for a sustainable environment. A report by town and county. Planning Association, Earthscan, London.

BORSDORF, A., 2002. Barrios cerrados en Santiago de Chile, Quito y Lima: tendencias de la segregación socio-espacial en capitales andinas. En: Latinoamérica: países abiertos, ciudades cerradas. Universidad de Guadalajara, México, pp. 581-610.

BREHENY, M., 1992. Sustainable development an urban form. Pion, London

CAMAGNI, R. (Ed.), 1991. Innovation networks: spatial perspectives. Belhaven Press, London.

CAPRON, G., 2002. Rassemblement et dispersion dans la ville latino-américaine; un nouveau espace public urbain, le cas du centre comercial. Cahiers des Ameriques Latines, 35: 41-56.

CASTELLS, M. 1995. La ciudad informacional. Tecnologías de la información, reestructuración económica y el proceso urbano-regional. Alianza Editorial, Madrid.
CASTELLS, M. 1996. La era de la información. Alianza Editorial, Madrid (Vol. 1: La sociedad red).

CASTElls, M., R. DORADO \& J. BORJA (Eds.), 1991. Las grandes ciudades en la década de los noventa. Ed. Sistema, Madrid

CASTRO, C.P, SARRICOLEA, P. Y NOVOA, J.. 2002. Áreas de expansión y su vulnerabilidad a amenazas naturales. La Serena, IV Región de Coquimbo. Anales de la Sociedad Chilena de Ciencias Geográficas, Santiago: 13-24.

CHARDON. A. 2002. Un enfoque geográfico de la vulnerabilidad en zonas urbanas expuestas a amenazas naturales; el ejemplo andino de Manizales, Colombia. Universidad Nacional de Colombia. Manizales.

COLES, E., D. et al. (ed.) 2000, Risk management and society. Advances in Natural Hazards and Technological Hazards Research. Kluwer Academic Publishers. London.

DE MATTOS, C. 1999. Santiago de Chile, globalización y expansión metropolitana: lo que existía sigue existiendo. Eure, 25 (76): $29-56$.

DEMATTEIS, G., 1998. Suburbanización y periurbanización. Ciudades anglosajonas y ciudades latinas. En: Monclús, F.J. (Ed.), La ciudad dispersa. Centre de Cultura Contemporania de Barcelona, Barcelona, pp. $17-33$.

ESCOLANO, S. 2002. Densidad de población y sustentabilidad en la ciudad de Zaragoza. En: Longares, A \& J. L Peña (Eds.), Aportaciones geográficas en memoria del Profesor L. Miguel Yetano Ruiz. Universidad de Zaragoza, Zaragoza, pp. 173-182.

FISHER, T. 2003. Differentiation of Growth Processes in the Peri-urban Region: An Australian Case Study. R.Urban Studies, . 40(3); 551 - 566. 
GIDDENS, A. 1990. The consequences of modernity. Polite Press, Cambridge.

JENKS, M.E., K. WILLIAMS \& E. BURTON (Eds.), 1996. The compact city a sustainable form?. E \& FN Spon, London.

LAGOS, M. 1997. Modelamiento espacial del riesgo de tsunami en la ciudad de Arica. Práctica profesional para optar al título de Geógrafo. Universidad Católica de Chile, Santiago, inédito.

MÄSKREY், A..1993. Los desastres no son naturales (compilador). La Red, Bogotá, 140 pp.

MCLAREN, D. 1992. Compact or dispersed? Dilution is no solution. Built Environment, 18: 268-284.

MERTINS, G. 2000. Ciudades medianas en América Latina: criterios, indicadores y el intento de un modelo de su diferenciación socio-espacial y funcional. Espacio y Desarrollo, 12: 13-23.

MONCLÚS, F. J., 1998. Suburbanización y nuevas periferias. Perspectivas geográfico-urbanísticas. En: Monclús, F.J. (Ed.), La ciudad dispersa. Centre de Cultura Contemporania de Barcelona, Barcelona, pp $5-15$.

NEWMAN, P. 1992. The compact city: an australian perspective. Built Environment, 18(4): 285-300.

ORTIZ, J. \& R. MORENO, 2002. Migraciones internas y diferenciación social en una ciudad de tañaño medio del sistema urbano chileno: el caso de La Serena en la Región
IV de Coquimbo Anales Soc. Chilena de CC. Geogr. (En prensa).

POWER, A. 2001. Social exclusion and urban sprawl: is the rescue of cities possible?. Regional Studies, 35(8): 731-742.

PREVOT, M. F. 1999. Amérique Latine: la ville fragmentée. Esprit, 258: 128-144.

SCHNELL, I. \& W. OSTENDORF (Eds.), 2002. Studies in segregation and desegregation, Ashgate, Aldershot.

SAATY, T. 1997. Toma de Decisiones para Líderes: El proceso analítico jerárquico en la toma de decisiones en un mundo complejo. Trad. Ed. RWS Publications, Pittsburgh.

THOMAS, C. 1980. Microzonificación sísmica de La Serena y Coquimbo. Memoria para optar al título de Ingeniero Civil. Departamento de Obras Civiles de la Universidad de Chile, Santiago, inédita.

THRIFT, N. 1987. The urban dimension of global restructuring. In: Henderson T. \& M. Castells (Eds.), Global restructuring and territorial development. Sage, Berverly Hills, CA, pp. 203-233.

THUILLIER, G. 2001. Le quartier enclos à Buenos Aires: quand la ville devient country. Cahiers des Ameriques Latines, 35: 41-56.

VÉLIZ, G. 1995. Conurbación La SerenaCoquimbo. Imprenta Editorial Rosales Hnos. Ltda., La Serena.

ZUMIN, L. 1994. Los estudios urbanos en la última década: entre la dimensión global y la dimensión local, Documents d'Anàlisi Geogràfica, 24: 181-200. 